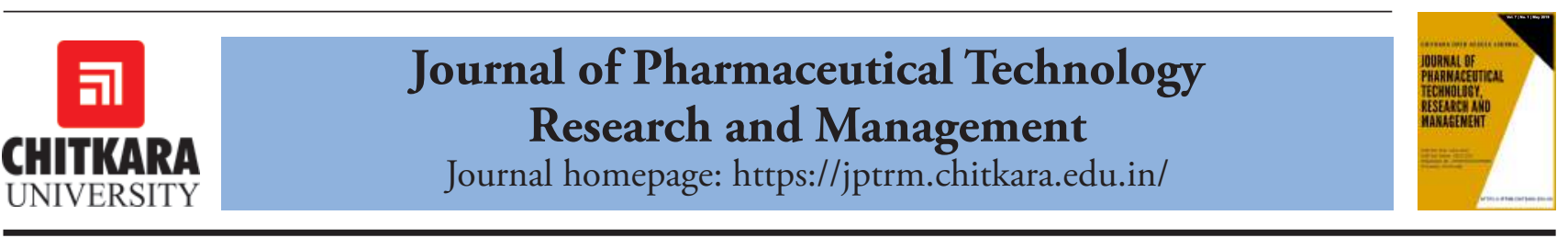

\title{
UV-Spectrophotometry - Multicomponent Mode of Analysis for Simultaneous Estimation of Brinzolamide and Brimonidine Tartrate in Bulk and Ophthalmic Formulation
}

Vikram L. Jadhav, Amod S. Patil, Suraj R. Chaudhari and Atul A. Shirkhedkar*

Department of Pharmaceutical Chemistry, R. C. Patel Institute of Pharmaceutical Education and Research, Shirpur, Dist.: Dhule (M.S.) India 425405

*Email:shirkhedkar@gmail.com

\section{ARTICLE INFORMATION}

Received: Dec. 07, 2018

Revised: Feb. 11, 2019

Accepted: March 15, 2019

Published online: May 10, 2019

\section{Keywords:}

Brinzolamide; Brimonidine tartrate; UV-

Spectrophotometry; Multicomponent mode of analysis; Validation

DOI: https://doi.org/10.15415/jptrm.2019.71005

\section{ABSTRACT}

Brinzolamide (BRZ) and Brimonidine Tartrate (BT) in combination are available as an ophthalmic suspension in the ratio of 5:1. A simple, reproducible and efficient method for the simultaneousdetermination of BRZ and BT in Bulk and Ophthalmic formulation has been developed. The absorbance was assessed at two wavelengths i.e. $252.40 \mathrm{~nm}$ ( $\lambda$ max of BRZ) and $246 \mathrm{~nm}(\lambda$ max of BT) in methanol. In this method, BRZ and BT executed linearity in the concentration range of $5-35 \mu \mathrm{g} / \mathrm{mL}$ and $3-18 \mu \mathrm{g} / \mathrm{mL}$, respectively at their respective $\lambda$ max. The developed method was found to be accurate, precise and rugged as marked by small values of \% RSD according to ICH guidelines.

\section{Introduction}

Brinzolamide (BRZ), chemically is (R)-4-(ethyl amino)-3, 4-dihydro-2-(3-methoxypropyl)-2 $H$-thieno $[3,2-\mathrm{e}]-1$, 2-thiazine-6-sulphonamide1, 1-dioxane (Figure 1a). It is a recent active compound which is helpful only for topical usage in the management of glaucoma $[1,2]$. Brimonidine Tartrate (BT), 5-bromo-N-(4,5-dihydro- $1 H$-imidazol-2-yl) quinoxalin-6-amine;(2R,3R)-2,3-dihydroxybutanedioic acid (Figure 1b). It is $\alpha 2$-adrenoreceptor agonists which lowers intra-ocular pressure (IOP) in patients with open-angle glaucoma or ocular hypertension (IP 2014, Merck index 2001). Literature review revealed few analytical methods

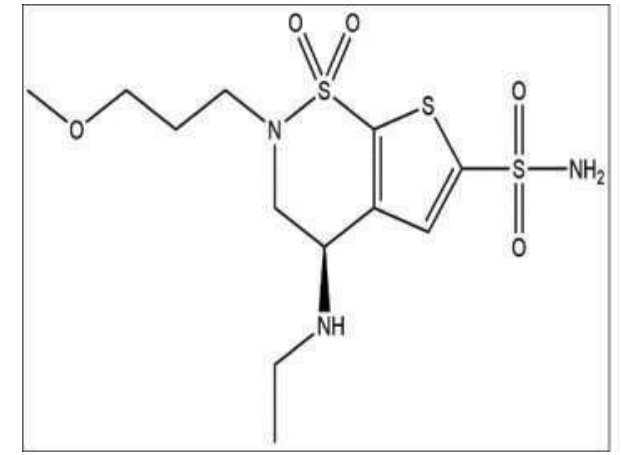

(a) such as UV-Spectrophotometry [4, 6], HPLC $[5,7,11]$, HPTLC [8, 6], LC-MS/MS [9] and Stability- Indicating UPLC [10] methods for measurement of BRZ and BT alone and in combination with other drugs. To our knowledge, in literature UV-Spectrophotometry- Multicomponent mode of analysis has not been reported so far for simultaneous determination BRZ and BT in pharmaceutical formulation Therefore, the novelty of present work is to establish new $[3,12,15]$, cost-effective, sensitive, precise and accurate method for the simultaneous estimation of BRZ and BT in combined ophthalmic dosage form by using multi-component mode of analysis [13, 15], 2018).

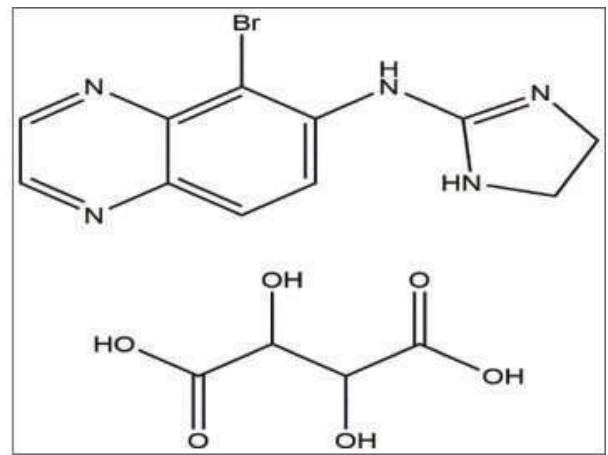

(b)

Figure 1. Chemical Structure of (a) Brinzolamide and (b) Brimonidine Tartrate 


\section{Materials and Methods}

\subsection{Chemicals and Reagents}

Pure Brinzolamide (BRZ) and Brimonidine tartrate (BT) were procured as a gift samples from Amneal Pharmaceutical Ltd. Ahmadabad, India and Alembic Pharmaceutical Ltd., Vadodara, India. AR grade methanol was obtained from Merck Ltd., Worli, India.

\subsection{Instrumentation}

A double beam UV-VIS spectrophotometer (UV-1601, Shimadzu, Japan) with $10 \mathrm{~mm}$ quartz cells was used. Analytical balance (Shimadzu AUX 120) was used for weighing purpose.

\subsection{Selection of Common Solvent}

Methanol (AR) was selected as common solvent for developing spectral features of both the drugs. The selection of the solvent was made after assessing the solubility in different solvents.

\subsection{Preparation of Stock Standard Solution and determination of $\lambda$ max}

Stock standard solutions of BRZ and BT were prepared separately by dissolving $10 \mathrm{mg}$ into $100 \mathrm{~mL}$ methanol to

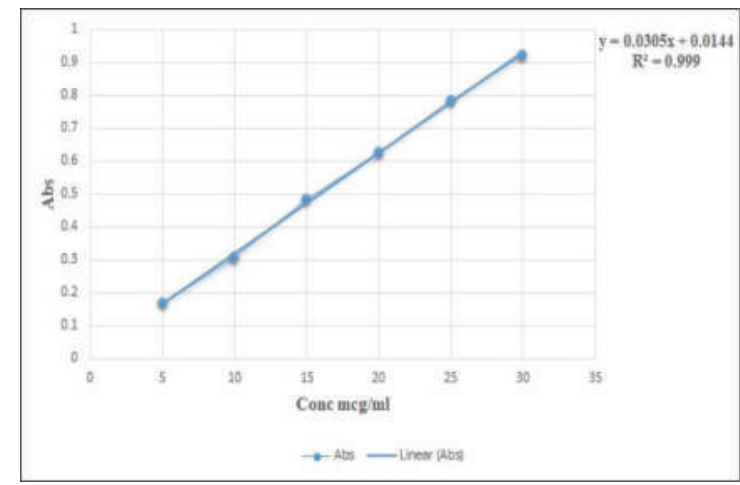

(a) obtain concentrations $100 \mu \mathrm{g} / \mathrm{mL}$ of each. From these stock solutions, working standard solutions having concentration $10 \mu \mathrm{g} / \mathrm{mL}$ of BRZ and $10 \mu \mathrm{g} / \mathrm{mL}$ of BT were prepared by proper dilutions. They were scanned in the UV- region i.e. $400-200 \mathrm{~nm}$.

\subsection{Study of Linearity Curves}

An appropriate volume of $\mathrm{BRZ}$ and $\mathrm{BT}$ in the range of $0.5-3.5 \mathrm{~mL}$ and $0.3-1.8 \mathrm{~mL}$ were transferred into series of separate $10 \mathrm{~mL}$ volumetric flasks and volume was made up to mark with methanol to get concentrations in the range of $05-35 \mu \mathrm{g} / \mathrm{mL}$ and $03-18 \mu \mathrm{g} / \mathrm{mL}$, respectively. The absorbance of BRZ and BT was measured at $252.40 \mathrm{~nm}$ and $246 \mathrm{~nm}$, respectively. Calibration curves were plotted as concentrations versus absorbance, given in Figure 2a (BRZ) and $2 \mathrm{~b}(\mathrm{BT})$.

\subsection{Multicomponent Mode of Analysis}

Six mixed standard solutions of BRZ and BT in the ratio of 1:5 were prepared in methanol as shown in Table 1. All the mixed standard solutions were scanned over the range of $400-200 \mathrm{~nm}$, in the multicomponent mode, using two sampling wavelength $252.40 \mathrm{~nm}(\lambda$ max of BRZ) and $246 \mathrm{~nm}(\lambda$ max of BT). The overlain spectra are shown in Figure 3. The data from these scans were used to determine the concentrations of two drugs in ophthalmic solution.

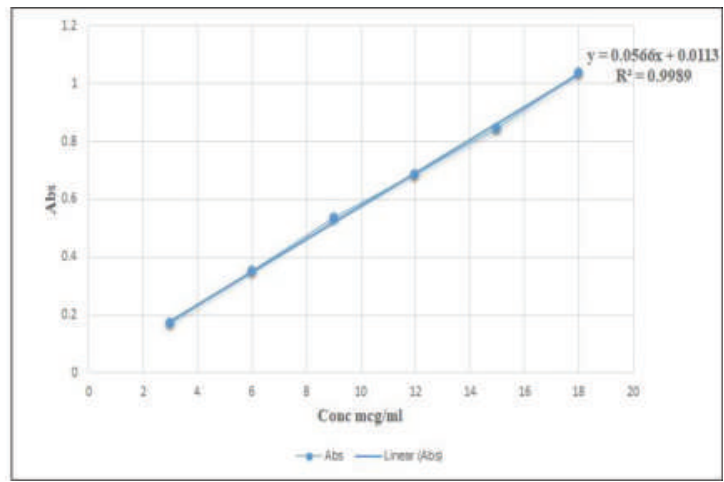

(b)

Figure 2. (a) Calibration curve for BRZ (b)Calibration curve for BT

Table 1. Mixed Standards of BRZ and BT

\begin{tabular}{lllllll}
\hline Drugs & I & II & III & IV & V & VI \\
\hline BRZ $(\mu \mathbf{g} / \mathbf{m L})$ & 0 & 15 & 25 & 30 & 35 & 35 \\
BT $(\mu \mathbf{g} / \mathbf{m L})$ & 7 & 3 & 5 & 6 & 7 & 0 \\
\hline
\end{tabular}




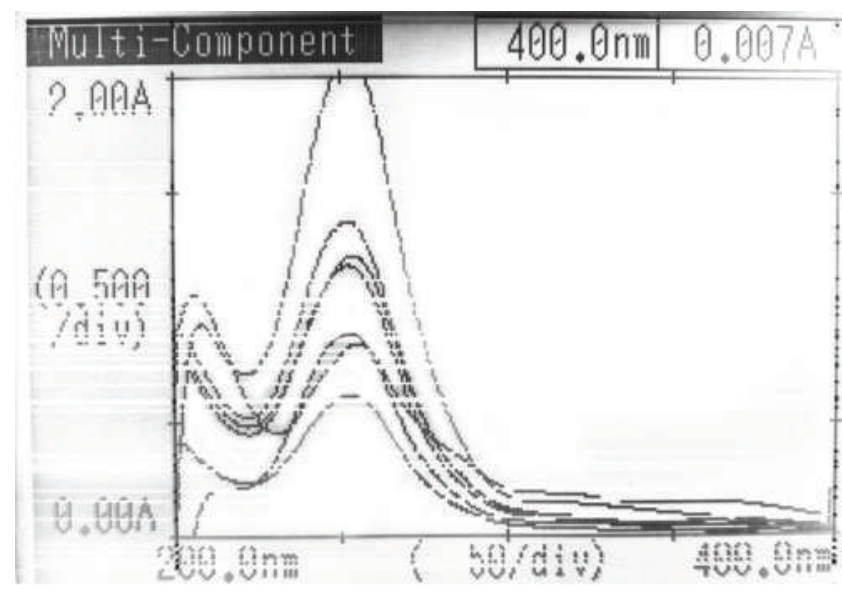

Figure 3. An overlain Spectra of Brinzolamide and Brimonidine Tartrate

\subsection{Analysis of Marketed Formulation}

For assay of marketed formulation, a volume of suspension equivalent to $10 \mathrm{mg}$ of BRZ and $2 \mathrm{mg}$ of BT accurately transferred into $100 \mathrm{~mL}$ volumetric flask containing 50 $\mathrm{mL}$ methanol, sonicated for $20 \mathrm{~min}$ and volume was made unto the mark with same solvent and filtered through Whatmann filter paper (no.41). Aliquot portion $1.0 \mathrm{~mL}$ was transferred into $10 \mathrm{~mL}$ volumetric flask and volume was adjusted to mark with the same solvent. The sample solution was scanned over the range $400-200 \mathrm{~nm}$, in the multicomponent mode; using two sampling wavelength 252.40 ( $\lambda$ max of BRZ) and $246 \mathrm{~nm}(\lambda \max$ of BT). The percent label claim was calculated and results are presented in Table 2.

Table 2. Analysis of Marketed Ophthalmic formulation

\begin{tabular}{lllll}
\hline Drugs & $\begin{array}{l}\text { Label } \\
\text { claimed } \\
{[\mathbf{m g}]}\end{array}$ & $\begin{array}{l}\text { \% Amount } \\
\text { found } \\
{[\mathbf{n}=\mathbf{6}]}\end{array}$ & $\pm \mathbf{S D}$ & \% RSD \\
\hline BRZ & 10 & 100.58 & 1.13 & 1.12 \\
BT & 2 & 100.94 & 0.50 & 0.49 \\
\hline
\end{tabular}

SD-Standard Deviation

$\%$ RSD-Relative standard deviation

$n$ - Number of determination (6)

\section{Validation of Method}

The method was validated in terms of accuracy, precision, repeatability and ruggedness as per the ICH guidelines [13].

\subsection{Accuracy/Recovery Studies}

The accuracy was demonstrated at three different levels. To the pre-analyzed sample solution of $15 \mu \mathrm{g} / \mathrm{mL}$ of BRZ and $3 \mu \mathrm{g} / \mathrm{mL}$ of BT, a known quantity of drug standards of BRZ and BT were added at 80, 100 and $120 \%$ level and reanalysed using proposed method. The analysis was repeated for three times at each level.

\subsection{Precision (Intra-day and Inter-day Variations)}

Intra-day precision was determined by analyzing the 20,25 and $30 \mu \mathrm{g} / \mathrm{mL}$ of BRZ and 4,5 , and $6 \mu \mathrm{g} / \mathrm{mL}$ of BT solutions for three times in the same day and Interday precision was determined by analyzing 20,25 and $30 \mu \mathrm{g} / \mathrm{mL}$ of BRZ and 4,5 and $6 \mu \mathrm{g} / \mathrm{mL}$ of BT of drug solutions daily for three consecutive days.

\subsection{Repeatability Studies}

Repeatability was determined by analyzing $15 \mu \mathrm{g} / \mathrm{mL}$ of $\mathrm{BRZ}$ and $3 \mu \mathrm{g} / \mathrm{mL}$ of BT for six times.

\subsection{Ruggedness}

Ruggedness of the proposed method was determined by analysis of aliquots from homogenous slot by two analyst using same operational and environmental conditions.

\subsection{Sensitivity}

Sensitivity of the proposed method was estimated in terms of Detection Limit (DL) and Quantitation Limit (QL). The $\mathrm{DL}$ and $\mathrm{QL}$ were calculated by the use of the equation,

$$
\mathrm{DL}=3.3 \times \frac{\mathrm{ASD}}{\mathrm{S}} \text { and } \mathrm{QL}=10 \times \frac{\mathrm{ASD}}{\mathrm{S}}
$$

where, 'ASD' is Average standard deviation of absorbance of the drug $(\mathrm{n}=3)$, taken as a measure of noise, and ' $\mathrm{S}$ ' is the slope of the corresponding calibration curve.

\section{Results and Discussion}

$\mathrm{BRZ}$ and BT in combination are available as an ophthalmic suspension in the ratio of 5:1. A simple, reproducible and efficient method for the simultaneous determination of BRZ and BT in Bulk and Ophthalmic formulation has been developed. The measurement of absorbanceat two wavelengths i.e. $252.40 \mathrm{~nm}, \lambda$ max of BRZ and $246.0 \mathrm{~nm}, \lambda$ max of BT in methanol were performed. In this method BRZ and BT followed linearity in the concentration range of $5-35 \mu \mathrm{g} / \mathrm{mL}$ 
for $\mathrm{BRZ}$ and $3-18 \mu \mathrm{g} / \mathrm{mL}$ for $\mathrm{BT}$ at their respective $\lambda$ max. The proposed method was applied for pharmaceutical formulation. The \% label claim for BRZ and BT was found to be 100.58 $\%$ and $100.94 \%$, respectively. The amount of drug estimated by method was found to be in good agreement with the label claim. The method was validated for accuracy, precision and ruggedness. Accuracy of the method was checked by recovery studies at three different levels i.e. $80 \%, 100 \%$ and $120 \%$. The $\%$ recovery of BRZ and BT was found to be 98.36 $99.11 \%$ and $99.82-100.0 \%$, respectively; the \% RSD values less than 2 indicative of accuracy of the method. The method was found to be precise as indicated by the inter-day, intra-day and repeatability analysis; showing \% RSD less than 2 . The results did not show any statistical difference between operators suggesting that method developed was rugged. The summary of validation parameters is presented in Table 3 .

Table 3. Validation parameters of BRZ and BT by proposed methods

\begin{tabular}{|c|c|c|}
\hline Parameter & BRZ & BT \\
\hline \multicolumn{3}{|l|}{ Linearity } \\
\hline $\begin{array}{l}\text { Linearity range } \\
(\mu \mathrm{g} / \mathrm{mL})\end{array}$ & $5-35$ & $3-18$ \\
\hline $\begin{array}{l}\text { Linearity } \\
\text { equation }\end{array}$ & $\begin{array}{l}Y=0.0305 X+ \\
0.0144\end{array}$ & $\begin{array}{l}Y=0.0035 X+ \\
0.0014\end{array}$ \\
\hline $\begin{array}{l}\text { Correlation } \\
\text { coefficient }\left(r^{2}\right)\end{array}$ & 0.9959 & 0.9990 \\
\hline \multicolumn{3}{|l|}{ \% Recovery } \\
\hline$\%$ RSD & 0.25 & 0.57 \\
\hline \multicolumn{3}{|c|}{ Precision [\% RSD] } \\
\hline Intra-day $[\mathrm{n}=3]$ & 0.82 & 0.41 \\
\hline Inter-day $[\mathrm{n}=3]$ & 1.12 & 1.164 \\
\hline $\begin{array}{l}\text { Repeatability } \\
{[\mathrm{n}=6]}\end{array}$ & 0.27 & 0.74 \\
\hline \multicolumn{3}{|c|}{ Ruggedness [\% RSD] } \\
\hline Analyst-I & 0.25 & 0.34 \\
\hline Analyst-II & 0.54 & 0.42 \\
\hline \multicolumn{3}{|l|}{ Sensitivity } \\
\hline DL & 0.12 & 0.22 \\
\hline QL & 0.38 & 0.65 \\
\hline
\end{tabular}

$\%$ RSD-Relative standard deviation

DL-Detection Limit

QL-QuantitationLimit

\section{Conclusion}

The developed method is simple, economic, accurate and precise and can be used for routine simultaneous analysis of BRZ and BT from its pharmaceutical formulation.

\section{Acknowledgement}

The authors are thankful to Dr. S. J. Surana, Principal, R.C. Patel Institute of Pharmaceutical Education and Research, Shirpur (M.S.), India for providing the required facilities to carry out this research work.

\section{Conflict of Interest}

The authors declare no potential conflict of interest.

\section{References}

[1] United states Pharmacopoeia 30 National formulary 25, United State Pharmacopeia Convention, 2007, 1551

[2] Indian Pharmacopoeia. Ministry of Health and Family Welfare, Government of India, the Indian Pharmacopoeial Commission, Ghaziabad, 2, 2014, 1201-1202.

[3] THE MERCK INDEX-An encyclopedia of Chemicals, Drugs, And Biologicals, 13th edition, MERCK \& CO., INC. Whitehouse Station, NJ, 2001, 1361-1362.

[4] Shah, P. A., Kadikar, A. S., Katira, R. M., Patel, K. G., and Gandhi, T. R. (2014). Simultaneous determination of Brinzolamide and Timolol maleate using three different spectrophotometric methods. World Journal of Pharmacy and Pharmaceutical Sciences, 3(2), 1955-1967.

[5] Khatun, R., and Islam, S. A. (2014). Development and validation of analytical method for simultaneous estimation of Brinzolamide and Timolol by HPLC from ophthalmic preparation. International Journal of Pharmaceutical Sciences and Research, 5(3), 1001. https://doi.org/10.13040/IJPSR

[6] Jain, P. S., Khatal, R. N., \&Surana, S. J. (2011). Development and Validation of First Order Derivative UV-Spectrophotometric Method for Determination of Brimonidine tartrate in Bulk and in Formulation. Asian Journal of Pharmaceutical \& Biological Research (AJPBR), 1(3).

[7] Shirke, R. R., and Pai, N. (2002). RP-HPLC determination of Brimonidine tartrate in Brimonidine tartrate eye drops. Indian drugs, 39(9), 484-486. 
[8] Mahajan, A., Athensia, F., Gandhi, S. V., and Deshpande, P. B. (2010). Development and Validation of High Performance Thin Layer Chromatographic Method for Estimation of Brimonidine Tartrate as Bulk Drug and in Ophthalmic Solutions.International Journal Chemical Technology and Research, 2(3), 1376-1379.

[9] Jiang, S., Chappa, A. K., and Proksch, J. W. (2009). $A$ rapid and sensitive LC/MS/MS assay for the quantitation of Brimonidine in ocular fluids and tissues. Journal of Chromatography B, 877(3), $107-114$.

https://doi.org/10.1016/j.jchromb.2008.11.009

[10] Sonalis, M. C., and Rajput, A. P. (2011). Development and validation of a new stability indicating analytical method for the determination of related components of Brimonidine tartrate in drug substances and drug product using UPLC, International Journal Pharmacy and PharmaceuticalScience, 3(1), 145-150.

[11] Phogat, A., Kumar, M. S., and Mahadevan, N. (2011). Simultaneous estimation of Brimonidine tartrate and Timolol maleate in nanoparticles formulation by RPHPLC. Int J Recent Adv Pharm Res, 3, 31-36.

[12] Jain P. S., Khatal R. N., Jivani H. N., and Surana S. J. (2011). Development and Validation of TLCdensitometry Method for Simultaneous Estimation of Brimonidine tartrate and Timolol maleate in Bulk and Pharmaceutical Dosage Form. Journal Chromatography Separation Techniques, 2(3), 1-5. https://doi.org/10.4172/2157-7064.1000113
[13] ICH Validation of analytical procedures: Text and methodology Q2 (R1), International Conference on Harmonization, 2005.

[14] Dhandar, A. G., Ganorkar, S. B., Patil, A. S., and Shirkhedkar, A.A. (2018). Development and Validation of UV Spectrophotometric Method for Simultaneous Estimation of Quinfamide and Mebendazole in in-house Pharmaceutical Formulation,Journal of Pharmaceutical Technology, Research and Management 6(1), 9-20. https://doi.org/10.15415/jptrm.2018.61002

[15] Patil, A. S., Shirkhedkar, A. A., Surana, S. J., and Nawale, P. S. (2011). Q-absorbance and multicomponent UV spectrophotometric methods for simultaneous estimation of propranolol hydrochloride and flunarizinedi hydrochloride in capsules. Der Pharma Chemica, 3(3), 404-408.

\section{Abbreviations}

- BRZ-Brinzolamide

- BT-Brimonidine Tartrate

- UV- Ultra Violet

- VIS- Visible

- $\mu \mathrm{g} / \mathrm{mL}$ - Micro Gram/ Milliliter

- DL-DetectionLimit

- QL-Quantification Limit

- ASD-Average Standard Deviation

- \% RSD-Percentage Relative Standard Deviation

- SD-Standard Deviation

- ICH-International Council on Harmonization 